SECTION 7. Mechanics and machine construction.

Aleksey Sergeevich Sevostyanov Undergraduate student

Togliatti State University, Russia sevalexey@yandex.ru

Igor Nikolaevich Bobrovskij

Ph.D., chief of laboratory

Togliatti State University, Russia bobri@yandex.ru

Aleksey Aleksandrovich Lukyanov Undergraduate student Togliatti State University, Russia a.lukyanov@,tehnomasch.ru

\title{
RESEARCH OF SURFACE PLASTIC DEFORMATION PROCESSING METHODS IN RUSSIA
}

Abstract: In this paper russian experience of machine parts processing technology with surface plastic deformation methods is presented. The main directions of further development of the technology are determined.

Key words: surface plastic deformation, roughness, oil absorption, lubricoolant.

Citation: Sevostyanov AS, Bobrovskij IN, Lukyanov AA (2014) RESEARCH OF SURFACE PLASTIC DEFORMATION PROCESSING METHODS IN RUSSIA. ISJ Theoretical \& Applied Science 8 (16): 24-29.

\section{ИССЛЕДОВАНИЕ МЕТОДОВ ПОВЕРХНОСТНО-ПЛАСТИЧЕСКОГО ДЕФОРМИРОВАНИЯ В РОССИИ}

Аннотация: В работе представлен российский опыт технологии обработки поверхностей деталей машин методами поверхностно-пластического деформирования. Определены основные направления дальнейтего развития технологии.

Ключевые слова: поверхностно-пластическое деформирование, иероховатость, маслоемкость, смазочно-охлаждающее технологическое средство.

Исследованиям в области обработки деталей поверхностно-пластическим деформированием (ППД) посвящены многие работы отечественных и зарубежных ученых $[1,2]$. Преимущество ППД в сравнении с другими методами финишной обработки заключаются в значительном снижении шероховатости (до Ra 0,04 мкм) и упрочнении приповерхностных слоев деталей, тем самым увеличивается долговечность всего изделия [3].

В основном процессы ППД внедряются на операциях по обработке ответственных деталей в мелкосерийном и единичном производстве, однако имеется опыт внедрения широкого выглаживания в массовое производство [4]. Целью данной статьи является обзор отечественного опыта применения технологии обработки ППД для финишной обработки деталей.

В Кузбасском государственном техническом университете имени Т.Ф. Горбачева В.Ю. Блюменштейн исследовал технологическое обеспечение деформационных параметров при обработке ППД мультирадиусным инструментом [5]. 


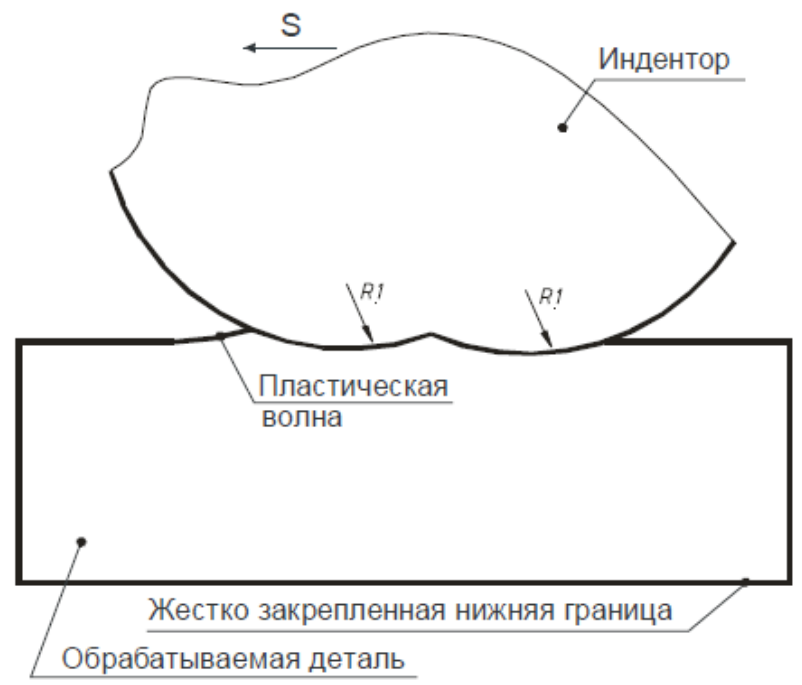

\section{Рисунок 1 - Постановка задачи конечно-элементного моделирования обработки роликом специального профиля третьего типа [5].}

Деформирующий элемент, первым входящий в контакт с поверхностным слоем, имел профильный радиус $\mathrm{R}=1$ мм и двигался относительно поверхности с действительным натягом $\mathrm{h}=0,02$ мм. Второй деформирующий элемент также имел профильный радиус $\mathrm{R}=1$ мм и имел смещение относительно 1-ого элемента в радиальном направлении на величину 0,03 мм. Таким образом, действительный натяг 2-го элемента относительно поверхности составил д $\mathrm{h}=0,05$ мм.

Анализ картины напряженного состояния показал наличие существенного взаимного влияния деформирующих элементов друг на друга: поля напряжений деформирующих элементов пересекаются, образуя объединенный очаг деформации. При этом в зоне задней контактной поверхности первого деформирующего элемента осевые и окружные растягивающие напряжения, свойственные этой зоне, вообще не успевают возникать вследствие влияния второго близкорасположенного деформирующего элемента. Наибольшие растягивающие напряжения возникают в осевом направлении в зоне задней контактной и внеконтактной поверхностей 2-го деформирующего элемента. Картина распределения касательных напряжений по мере продвижения вдоль очага деформации представлена несколькими зонами.

Наибольший перепад всех компонент напряжений наблюдается в зонах при вершинах деформирующих элементов. Здесь высокие значения сжимающих напряжений в районе передних контактных поверхностей переходят в околонулевые или растягивающие напряжения в районе задних контактных поверхностей.

Относительная деформация в основном локализована в области передних контактных и внеконтактных поверхностей деформирующих элементов.

Анализ показал, что при обработке специальным роликом с профилем 3-его типа имеется 5 участков квазимонотонной деформации, в то время как при обработке традиционным ППД обнаруживается лишь 3 участка.

Накопление деформации и исчерпание запаса пластичности носит двухступенчатый характер. При этом накапливаются значительные степени деформации сдвига 3..3,2 при докритических значениях степени исчерпания запаса пластичности $0,6 . .0,7$ (рисунок 2). Рост накопленных параметров практически прекращается в районе вершины второго деформирующего элемента.

Установлено, что при обработке роликом специального профиля третьего типа программа нагружения также имеет две выраженных ступени, обусловленные наличием 2x деформирующих элементов (рисунок 3 ). 
Накопление деформаций происходит в условиях сложного изменяющего напряженного состояния. Так, показатель схемы напряженного состояния изменяется от 0,577 до $-2,7$ и далее до -0,5 для первого профиля; далее закономерности изменения повторяются.

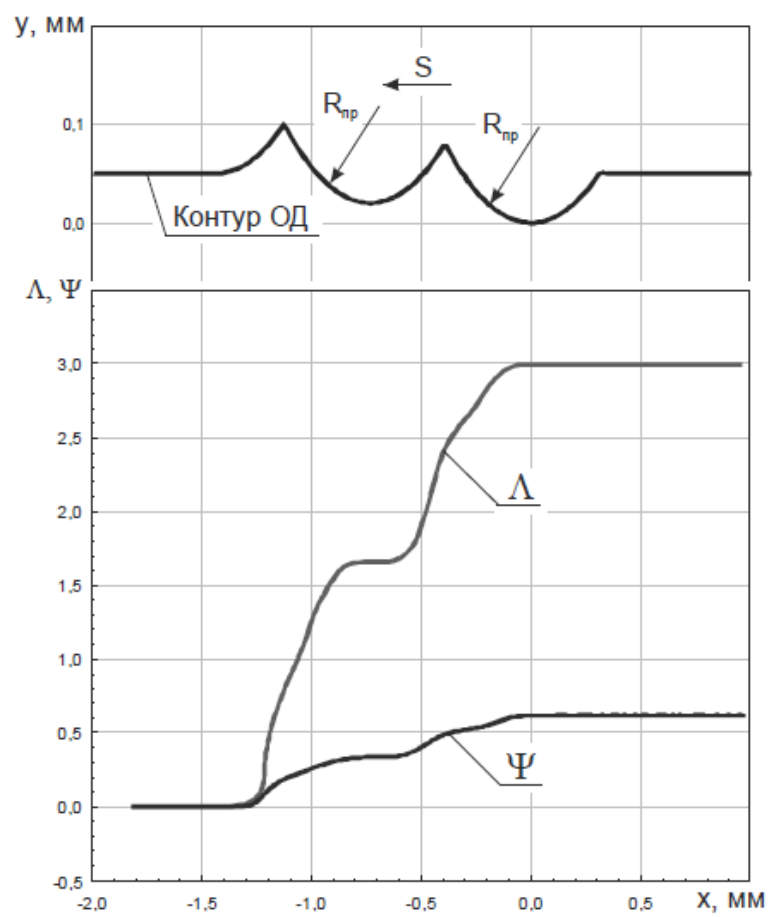

Рисунок 2 - Распределение накопленных значений степени деформации сдвига и степени исчерпания запаса пластичности [5].

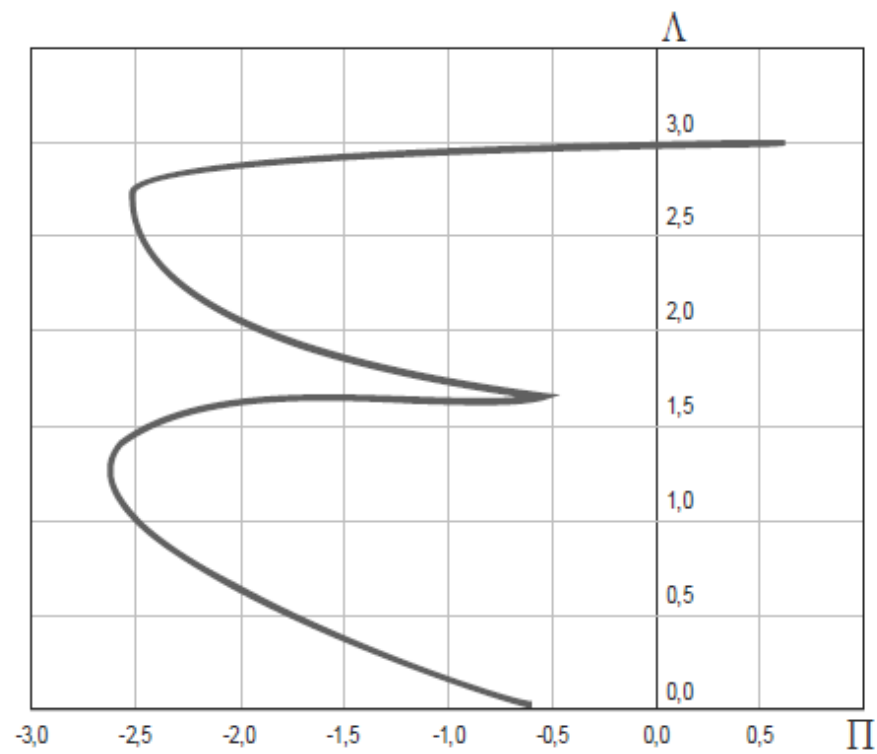

Рисунок 3 - Зависимость накопленной степени деформации от показателя схемы напряженного состояния П (программа нагружения) [5].

Очевидно, что применение мультирадиусного профиля позволяет создать оригинальную схему выглаживания с более мощным очагом деформации.

В Курганском государственном университете коллектив под руководством В.П. Кузнецова исследовал моделирование и формирование плосковершинного микрорельефа поверхностей трения со смазочными микрокарманами при многоцелевой обработке деталей [6]. 
Для обеспечения плосковершинного микрорельефа поверхности заготовки со смазочными микрокарманами разработаны способ и технология многопереходной обработки поверхностей трения, состоящая из следующих этапов:

1. Предварительное формирование микропрофиля поверхности трения высокоточной детали чистовым точением и выравнивающим выглаживанием.

2. Деформирующее профилирование смазочных микрокарманов на поверхности трения мультиинденторным инструментом.

3. Формирование плосковершинного микропрофиля поверхности со смазочными микрокарманами финишным полирующим выглаживанием.

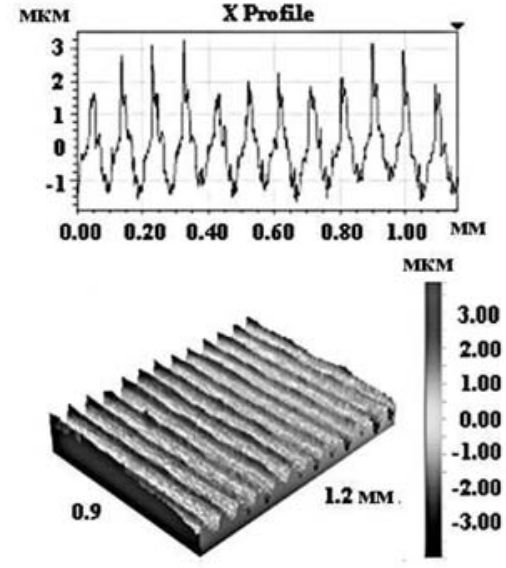

$a$

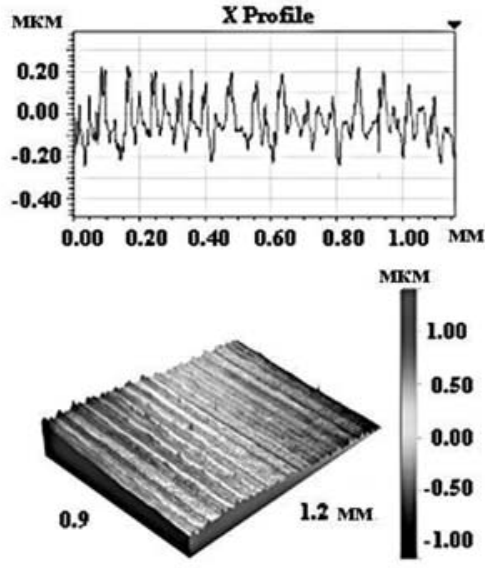

6

Рисунок 4 - 2D профилограммы и 3Dтопография поверхности трения детали:

a) после точения; б) предварительного выглаживания [6].

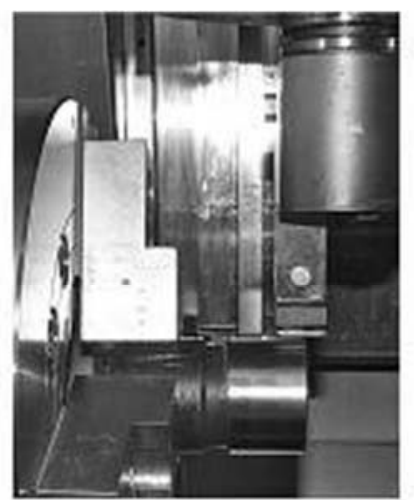

$a$

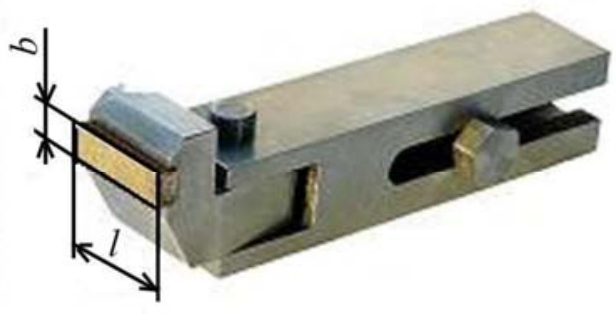

$\sigma$

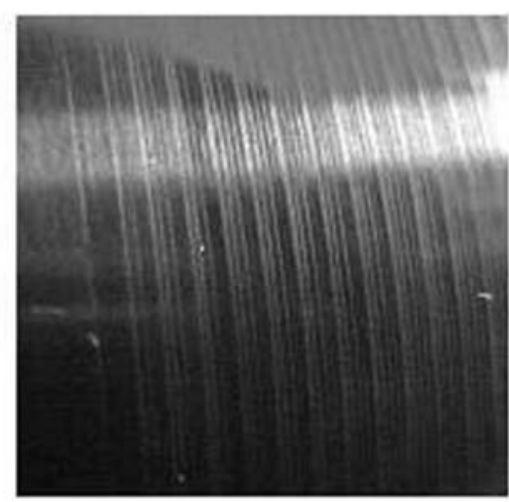

B

Рисунок 5 - Формирование смазочных микрокарманов винтового типа мультиинденторным инструментом: а) обработка тестовой детали; б) мультиинденторный формирователь смазочных микрокарманов; в) фрагмент поверхности тестовой детали после обработки [6]

В рассматриваемой статьей представлены результаты исследования фактической маслоемкости поверхности после каждого из финишных переходов многоцелевой обработки, проведенные с помощью электронного сканирующего микроскопа Tescan MIRA 3 LMU (табл. 1). 
Таблица 1

Объем смазочных микрокарманов

\begin{tabular}{|c|c|c|}
\hline \multirow{2}{*}{ Обработка } & \multicolumn{2}{|c|}{ Средний объем смазочных микроканалов } \\
\cline { 2 - 3 } & Абсолютное значение, мкм ${ }^{3}$ & Удельный объем мкм мкм $^{2}$ \\
\hline Точение & 207299,6 & 1,433 \\
\hline $\begin{array}{c}\text { Предварительное } \\
\text { выглаживание }\end{array}$ & 43192,6 & 0,818 \\
\hline $\begin{array}{c}\text { Деформирующее } \\
\text { профлирование }\end{array}$ & 357684,2 & 2,473 \\
\hline Финишное выглаживание & 188685,4 & 1,305 \\
\hline
\end{tabular}

Применение в высокотехнологичном машиностроении прецизионных токарнофрезерных центров с ЧПУ позволяет изготавливать сложные и ответственные детали за один установ, эффективно сочетая различные виды механической обработки с финишной обработкой поверхностей выглаживанием [7]. Однако практика выглаживания функциональных поверхностей деталей на многоцелевых станках инструментом с упругим демпфером показала, что выработанные практические рекомендации по режимам обработки не позволяют эффективно управлять качеством поверхностей деталей из коррозионностойких сталей.

Одной из основных проблем при формировании выглаживанием субмикрошероховатых поверхностей деталей со средним арифметическим отклонением профиля $\mathrm{Ra}<100$ нм является необоснованное назначение усилия обработки [8]. Существующие расчетные зависимости силы выглаживания основаны, как правило, на закономерностях, полученных при статическом вдавливании индентора в поверхность заготовки, и не учитывают комплексное влияние шероховатости обрабатываемой поверхности и подачи [9].

\section{Выводы}

Текущие отечественные исследования обработки методами ППД сосредоточены на применении инструментов различной формы для перераспределения напряжений при обработке, как предложено в статье В.Ю. Блюменштейна [5]. Это позволяет получить поверхность лучшего качества. Многоинструментальная обработка, с использованием совмещенной лезвийной обработки и обработки методом ППД позволяет обеспечить необходимую маслоемкость поверхности, данное исследование приведено в статье В.П. Кузнецова [6].

Кроме этих способов исследуется возможность использования гибридной обработки с различными методами воздействия на зону обработки для снижения сил трения [10]. При снижении сил трения температура зоны обработки не будет превышать предельно допустимого значения, что, в последствии, позволит отказаться от использования смазочно-охлаждающих технологических средств (СОТС) при финишной обработке. Таким образом, отказ от СОТС позволит значительно сократить затраты на производство изделия, позволит повысить безопасность труда и экологичность производственного цикла.

Проведение научно-исследовательской работы осуществляется при поддержке гранта Президента Российской Федеращии МК-6076.2013.8.

\section{References:}

1. Bobrovskiy NM, Bobrovskiy IN, Ezhelev AV, Mel'nikov PA (2012) Tehnologiya obrabotki detaley poverhnostno-plasticheskim deformirovaniem bez primeneniya smazyvayusche- 
ohlazhdayuschih tehnologicheskih sredstv. Samarskiy nauchnyy centr RAN, Samara, ISBN 987-5-93424-598-7, pp. 142.

2. Bobrovskiy NM (2008) Razrabotka nauchnyh osnov processa obrabotki detaley poverhnostno-plasticheskim deformirovaniem bez primeneniya smazochno-ohlazhdayuschih zhidkostey. Tol'yatti: Tol'yattinskiy gosudarstvennyy universitet, pp. 170.

3. Bobrovskiy IN, Mel'nikov PA, Bobrovskiy NM, Luk'yanov AA, Ezhelev AV (2012) Tehnologicheskoe obespechenie tribologicheskih svoystv sal'nikovyh sheek detaley mashin. Izvestiya Samarskogo nauchnogo centra Rossiyskoy Akademii Nauk, t.14, No1(2), pp. 340343. URL: http://www.ssc.smr.ru/media/journals/izvestia/2012/2012_1 340_343.pdf (date of access: 29.08.2014).

4. Mel'nikov PA (2008) Povyshenie ieffektivnosti tehnologii vyglazhivaniya shirokim samoustanavlivayuschimsya instrumentom bez smazochno-ohlazhdayuschey zhidkosti. avtoref. dis. kand. tehn. nauk. Samara: Samarskiy gosudarstvennyy tehnicheskiy universitet, pp. 20.

5. Blyumenshteyn VY (2012) Tehnologicheskoe obespechenie deformacionnyh parametrov pri obrabotke PDD mul'tiradiusnym instrumentom. Polzunovskiy al'manah, No 1. pp. 142-144.

6. Kuznecov VP, Dmitrieva OV (2011) Modelirovanie i issledovanie formirovaniya ploskovershinnogo mikrorel'efa poverhnostey treniya so smazochnymi mikrokarmanami pri mnogocelevoy obrabotke detaley. Izvestiya Tomskogo politehnicheskogo universiteta, t.319, No 2, pp. 35-40.

7. Luk'yanov AA, Bobrovskiy NM, Bobrovskiy IN, Mel'nikov PA, Ezhelev AV (2013) Napravleniya razvitiya poverhnostno-plasticheskogo deformirovaniya detaley mashin. Mezhdunarodnaya nauchno-prakticheskaya konferenciya «Sovremennye napravleniya teoreticheskih i prikladnyh issledovaniy 2013», Odessa: KUPRIENKO, t.3, No1, pp. 56-68.

8. Ezhelev AV, Bobrovskiy IN, Luk'yanov AA (2012) Analiz sposobov obrabotki poverhnostno-plasticheskim deformirovaniem. Fundamental'nye issledovaniya, No6 (chast' 3), pp. 642-646. URL: http:/elibrary.ru/download/99416024.pdf (date of access: 29.08.2014).

9. Bobrovskiy NM, Ezhelev AV, Mel'nikov PA, Bobrovskiy IN (2012) Ustroystvo dlya giperproizvoditel'noy finishnoy obrabotki poverhnostey detaley vyglazhivaniem. Izvestiya Samarskogo nauchnogo centra Rossiyskoy akademii nauk, t.14, No 6-1, pp. 93-96.

10. Bobrovskiy NM, Mel'nikov PA, Bobrovskiy IN, Ezhelev AV, Luk'yanov AA (2013) Issledovaniya vliyaniya «zelenoy» proizvodstvennoy tehnologii obrabotki vyglazhivaniem na pozharobezopasnost', iekologiyu i zdorov'e cheloveka. Izvestiya Samarskogo nauchnogo centra Rossiyskoy Akademii Nauk, t.15, No3-6, pp.1731-1733. URL: http://www.ssc.smr.ru/media/journals/izvestia/2013/2013 3 1731 1733.pdf (date of access: 29.08.2014). 